Abstract

\title{
Novel Anticancer Capacities of Saffron ${ }^{+}$
}

\author{
Amr Amin \\ Biology Department, UAE University, Abu Dhabi 15551, United Arab Emirates; a.amin@uaeu.ac.ae \\ + Presented at the 2nd International Conference on Natural Products for Cancer Prevention and Therapy, \\ Kayseri, Turkey, 8-11 November 2017.
}

Published: 15 November 2017

\begin{abstract}
Thanks to poor diagnosis and very limited treatment options, hepatocellular carcinoma (HCC) continues to lead the list of cancer-leading causes of death worldwide. Therefore, alternative therapy is crucial to control HCC. Our group has investigated the anticancer effects of the saffron's main active ingredient "safranal" against HCC using in vitro, in silico, and network analyses. In addition to the unique and differential cell cycle arrest, safranal showed pro-apoptotic effect through activation of both intrinsic and extrinsic initiator caspases implicating ER stress-mediated apoptosis. Gene set enrichment analysis provided consistent findings where unfolded protein response (UPR) was among the top terms in up-regulated genes in response to safranal treatment. Thus, proteins involved in ER stress and autophagy were regulated through safranal treatment to induce UPR and autophagy-mediated cell death in HepG2 cells.
\end{abstract}

Keywords: saffron; ER-stress; unfolded protein response

Conflicts of Interest: The authors declare no conflict of interest.

(C) 2017 by the authors. Licensee MDPI, Basel, Switzerland. This article is an open access article distributed under the terms and conditions of the Creative Commons Attribution (CC BY) license (http://creativecommons.org/licenses/by/4.0/). 